\title{
The Application of Voice Control Technology in Piano Playing Xianji Liao ${ }^{1, a}$ \\ ${ }^{1}$ Capital Normal University, Music College, Beijing, China, 100048 \\ ${ }^{a}$ email,
}

\author{
Keywords: Specific Use; Sound Control Technology; Piano Playing
}

\begin{abstract}
To play a good piano song, we must first control and master the playing sound. Players in the performance to achieve with the audience emotional and spiritual resonance not only to have superb playing skills but also have a good sound control, through the sound to control the sound effects, to achieve the perfect performance in the performance, so that the audience can really feel to the piano to bring the beauty and mind and emotional touch. This article is through the analysis and elaboration of how to control and use the sound in order to achieve the perfect performance.
\end{abstract}

\section{Introduction}

When playing the piano, in order to achieve the effect of playing, so that the music works to express the player's inner feelings, must be played by virtue of the beautiful piano to express and pass, and the sound effect is passed we usually The tone of the perfect transmission and expression in the piano must have to master and use, and usually, the decision to play the sound control of the main two reasons, the first is the player's skill skills proficiency; The second is the player's aesthetic ability to play the sound. Therefore, under normal circumstances, the player if there is a delicate emotion, deep thinking, rich imagination and innovative creativity can be accurately grasp the sound of the aesthetic, but also to achieve the emotional resonance with the audience [1].

\section{Sound and Sound Control}

Sound refers to the sound of the characteristics of the feeling, but also refers to the sound or sound color. Different tones determine different sounds, all the instruments and sound of the object can make a sound, but the sound is only one pitch, and there are a lot of overtone, these overtone is because many different frequencies and the speed of vibration of objects And this is because all of the overtones produced a variety of sounds, it is precisely because these sounds can really tell what sound comes from what object, what is the instrument issued, so the different sounds also decided Different piano pieces. And for the piano sound refers to the piano in the performance of the sound effect, playing in the process of different sound effects will make people have different associations and produce a different sense of contrast, so as to feel the different playing beauty.

The sound of the piano is very wide, the sound is also very rich, as Nergotz said the same: "piano is a pianist performance means (like a painter's painting, through the color, line and color performance The same), beautiful piano is a major means of expression "[2]. So, the sound is just for the performance of music and services, and need to show what kind of sound, which depends on the music to express the emotional and content decisions, therefore, different types of music, different periods of music, different content of the expression of the music works, different emotional expression of the music works, different people to create music works, different geographical environment of the creation of music works, different national cultural background of the works of music and so on through the different playing skills to get the specific expression of the music needed to produce the sound, which is what we often say that the sound control. Piano in the process of playing, in order to perfectly express the feelings of music works, you must skillfully master the playing skills, in order to get the perfect sound, control sound. In the process of playing the piano, in order to control the sound, the perfect performance of the harmony of the sound, you must master the piano playing in the pedal technology and touch technology. 


\section{The Specific Use of Pedal Performance Technology in the Sound Control}

In the process of playing the piano, to control the sound, master and control the pedal of the playing technology is very important, usually in the piano performance process pedal technology is more complex but very detailed, according to different tone requirements The standard is different and different classification, for example, in the process of playing, according to the pedal depression depth, you can pedal is divided into: 3/4 pedal technology, 1/2 pedal technology, 1/4 pedal technology, the whole Pedal technology and so on. According to the speed of the pedal and pedal speed, the pedal slowly depress and quickly lift the technology, pedal quickly depressed and slowly lift the technology, pedal slowly depressed slowly technology, pedal quickly depressed fast lift technology and other four pedal technology [3]. In addition, there are a lot of pedal technologies used to produce some special timbre effects, such as pedal technology, cutting pedal technology, rhythm pedal technology, finger pedal technology, jitter pedal technology. During the performance of the piano, the control of the timbre is achieved through the mastery of these pedal techniques, and in the performance of the pedal technique, it is necessary to perform different pedal techniques according to the different styles of the musical works and the different periods the use.

Baroque Period. For the Baroque piano works, a lot of music works more rigorous, to express the kind of clear and clear emotions, so the work of the sound must be strong, delicate and sensitive. So in the process of playing Bach polyphonic piano works, must be based on the work itself to decide what kind of pedal technology to use to express a variety of sounds, because the Bach polyphonic piano is the then harpsichord and ancient Piano written While the harpsichord and the piano did not have the pedal, but the sound of the strings used in the playing process was longer than the sound of the modern piano's sustain pedal, so if the Bach works were not The use of pedals, then the performance of the performance of the sound will be very monotonous, and did not have the original in the plow steel piano and the ancient piano played the effect of Bach works. Therefore, in the performance of the Bach piano works, we must learn through the pedal technology to express the work, so that Bach works in the process of playing each of the sound is very coherent and clear, the use of pedal in the process cannot step Is too deep to prevent the emergence of too strong overtone and affect the effect of the entire playing sound [4].

The Period of Classicalism. For the classical period of piano music works, a lot of music works are more rigorous and strong expression, so different works need to use different pedal technology. For example, in Beethoven's work, it can be said that Beethoven is "the use of the pedal requirements must be able to clearly feel the first well-known piano composer." Beethoven a lot of piano music, the need to use the piano pedal of the place has done a detailed note. Therefore, in the Beethoven's playing work, the pedal is used very frequently, and in order to ensure that the sound of the music works more rich and full, in order to phrase more coherent, in order to contrast more obvious, in order to produce more complex voice, in order to So that the concert more coordinated, in order to play more smooth and harmonious, need to use a lot of pedal technology. So that in the performance process through the vigorous voice, vividly expressed Beethoven piano works in the passion of emotion. Therefore, in the process of playing the piano, master the pedal of the technology will be conducive to the perfect presentation of the sound of music [5].

Romantic Period. For the romantic period of the piano music works, a lot of music to express the feelings of the more intense, the performance of the rich color, emphasizing the idea is more comprehensive, so the whole process of playing the need for sound "processing and coloring" Through the use of different pedal technology to get the kind of beautiful and thick, thick and not bright tone effect. For example, when playing Liszt's piano works, because Liszt's piano works is a stunning, piano-style piano performance: so the performance of the process of showing a loud volume, fast speed, Wild momentum, brilliant skills. His highly personalized, glorious, piano-style performance requires skill in the various pedals, and the style of the work and the expression of the work by the flexibility of the pedal technique during the performance process Variety of sound effects, so in Liszt's piano performance process also fully demonstrated the use of the pedal of the performance of the sound played a very important role.

Impressionist Period. For the piano music works of the Impressionist period, many of the 
works with a certain poetic expressed a hazy beauty, showing the feelings of more subtle. Debussy's piano works in the small mark on the pedal, but in his work during the performance of the pedal down, lift the priorities are demanding, in Debussy's playing process, it is necessary to Playing the harmonies, bass, rhythm and so on to change the pedal, attaches great importance to the use of shallow pedals, through the use of the pedal to express the kind of soft art in the mood. For example, in the process of playing Debussy's "Grenada Night" song, the pedal of the use of high technical requirements, must be used to step on the pedal, but also continue to quickly change, in order to Gran the night of the kind of looming mood of the night to express it. Therefore, in the process of playing the piano, to control the sound must use the pedal technology, only skilled and flexible use of pedal technology, to express the different periods, different backgrounds to play the work to show the different views and expression of different emotions [4].

\section{The Specific Use of Touch Technology in the Voice Control}

In order to obtain the desired sound of the piano works, in addition to skilled master pedal technology, but also need to master the superb touch technology, through the application of touch technology to complete the sound control. Touch technology is the core technology in the process of piano playing, referring to: during the playing process, the finger in front of the action to prepare the keys and the movement of the keys during the control. In the process of playing the piano keys on the keys of the important part of the finger in the course of the movement of the state, including the performance of the hand shape, touch the process of playing slowly and so on. Therefore, the different use of the key technology, the resulting tone control is also different.

The Key Height during Playing. The height of the touch key during the performance of the piano mainly refers to the height of the front face of the finger before the finger is played in the piano. From the point of view of the height of the touch, the touch can be divided into low finger and high finger touch keys in two ways. Low finger touch refers mainly to: fingers close to or close to the piano keys, and then force down the process of pressing the keys. Low finger touch can be broken down into: stickers and close to the keys and other two touch keys. High finger touch keys mainly refer to: the fingers hanging in the top of the keys down the process of knocking the keys. High finger touch can be broken down into "hit" "throw" two touch keys [5]. The advantage of the low finger touch is that the finger has a strong control force on the keyboard in the process of playing the track can be more consistent, accurate sound quality is smooth and uniform. The advantages of high finger touch keys are: in the course of the game can make the third joint full of fingers, with a strong explosive force, through the active and vigorous movement of the hammer to quickly hit the strings, the sound is also relatively crisp and Bright. So the height of the touch in the process of playing the different, the resulting sound effects are not used [5].

Touching Intensity in the Process of Playing. In the piano playing the process of touching the intensity of the main refers to: the fingers in the process of playing the moment the use of the power of touch. Touch the intensity of different, resulting in different sound effects, touch the appropriate pressure, the sound performance is relatively gentle, the touch of the intensity of the works show the feelings of the more magnificent atmosphere, and if the intensity is small, then it will Produce a relatively small tone, to express the emotions will be more soothing, his right to the delicate emotions, in the process of playing through the touch of the touch button can be a good control of the tone of the expression, and the intensity of the use of moderate, just right, it will make the music works to obtain the perfect sound effect, so that the performance of the work more vividly, more fluent, more fascinating, immersive into the works to express the mood.

Touch Speed in the Process of Playing. The speed of the touch during the performance of the piano mainly refers to the time during which the finger is in contact with the key and then to the pop-up point during the playing process. Usually the speed of playing according to the point of view, the speed of the keys is usually divided into: slow touch and fast touch two. Slow keys are usually in the performance of the performance of the process are relatively weak

And so on, used to lyrical slow pace of music, through the slow pace of playing the touch speed to express a relatively soft but not scattered sound, playing classical period or Baroque period of 
piano works, often using this playing technique. The fast-paced touch speed in the performance process, the transmission of the sound short and clear, flexible, express the feelings of the more bright, crisp, vigorous, heavy. Fast-paced playing speed is suitable for playing lively, cheerful piano works; more used to play singing, coherent phrases.

The Depth of the Key during the Playing Process. The depth of the touch in the piano playing process mainly refers to the two types of piano playing in the process, the finger presses the depth of the keys to sink, usually including the keys do not play in the end and the keys in the end. Keys do not play in the end is also called "shallow touch", the keys in the end, also known as "deep touch key." According to the different depth of the touch keys, playing out the tone effect is also different in the playing process must master the depth of the touch, find a suitable point in order to ensure the best pronunciation point in order to ensure that the works in the expression process In the sound out, both with the "soft" and "weak" and other characteristics, but also more "through" so that the audience can clearly hear the sound of the works expressed, so to master the touch technology must go through a long time to try to figure out And exercise, the performance of the sound will not appear "virtual" and "floating" [6].

\section{Conclusion}

All in all, in the process of playing piano tracks, in order to achieve the perfect performance of music works, it is necessary to highlight the effect of the sound, the player only in the accurate understanding of the music on the basis of the work, the rational use of pedal technology and touch technology, and emotional to play, in order to make smooth, full, clear, bright, heavy The sound effects flow out of the fingers, so that the performance of the tracks like the picture slowly appear in front of the audience, so only by clever use of piano playing in the tone control technology, can really make the piano technology sublimation for the piano art.

\section{References}

[1] Pan Hanchao; Master of piano improvisation accompaniment and allocation should pay attention to several issues [J]; Literature Education (middle); 201004

[2] [Sue] Henry Gustavovich Niegosz, Wang Qizhang, Wu Peihua Translated: "On Piano Performing Arts", People's Music Publishing House 1963, p. 79.

[3] Li Lang; on the piano playing psychological tension and relaxation [J]; music exploration; 2010 01 [3] Wang Linfei; Zheng Xiaomei; feel the charm of music - Beiduo Fen "third symphony" The fourth movement as an example [J]; big stage;

[4] Feng Li. In the piano playing with the sound, the intensity of expression of feelings [J]. Talent, 2011 (13)

[5] Wang Ying. Sound aesthetic in the piano playing in the discussion [J]. Modern communication, 2014 (6) 73-74

[6] Liu Xiaojing. Piano playing in the sound aesthetic research [J]. Drama House, 2014 (7) 128-129. 